\title{
Prevalence of serum celiac antibody in patients with IBD in Japan
}

\author{
Chikako Watanabe $\cdot$ Shunsuke Komoto $\cdot$ Ryota Hokari $\cdot$ Chie Kurihara $\cdot$ Yoshikiyo Okada \\ Hideaki Hozumi $\cdot$ Masaaki Higashiyama $\cdot$ Atsushi Sakuraba $\cdot$ Kengo Tomita Yoshikazu Tsuzuki • \\ Atsushi Kawaguchi $\cdot$ Shigeaki Nagao $\cdot$ Sho Ogata $\cdot$ Soichiro Miura
}

Received: 1 January 2013/Accepted: 18 May 2013/Published online: 12 June 2013

(C) Springer Japan 2013

\begin{abstract}
Background Although the incidence of inflammatory bowel diseases (IBD) in Japan has increased, the prevalence of celiac disease is considered very low with the lowest genetic disposition. IBD is reported as the most common comorbidity because of the high positive rate of serological celiac markers. The aim of this study was to examine the current incidence of celiac disease, especially in IBD patients in Japan, where both wheat consumption and incidence of IBD have increased.

Methods A total of 172 patients with IBD and 190 controls in Japan were screened for serum antibody of tissue transglutaminase and deaminated gliadin peptide. In seropositive patients, HLA testing and upper gastrointestinal endoscopy with duodenal biopsy was performed. Some of the sero-positive patients started a gluten-restricted or unrestricted diet, and serological change was determined.

Results The positivity of both serum antibodies was significantly higher in IBD and correlated with disease activity. However, no biopsy-defined or HLA-defined true celiac disease was found. A decrease in serum antibody titers was observed with a gluten-restricted diet.
\end{abstract}

C. Watanabe $(\bowtie) \cdot$ S. Komoto $\cdot$ R. Hokari - C. Kurihara

Y. Okada - H. Hozumi - M. Higashiyama - K. Tomita ·

Y. Tsuzuki $\cdot$ A. Kawaguchi $\cdot$ S. Nagao $\cdot$ S. Miura

Department of Internal Medicine, National Defense Medical

College, 3-2 Namiki, Tokorozawa, Saitama 359-8513, Japan

e-mail: chikakow@ndmc.ac.jp

\section{A. Sakuraba}

Section of Gastroenterology, Hepatology and Nutrition,

University of Chicago, Chicago, USA

S. Ogata

Department of Pathology and Laboratory Medicine,

National Defense Medical College, Tokorozawa, Japan
Conclusions Despite the increased incidence of IBD and high positivity for serum celiac antibody in Japanese IBD patients, no true-positive celiac disease was noted, suggesting the presence of gluten intolerance in these populations.

Keywords Celiac disease $\cdot$ Japanese $\cdot$ Inflammatory bowel diseases - Gluten

\section{Introduction}

The prevalence of celiac disease has significantly risen over the past years in European countries. More recently, similar prevalence has been reported from some Asian and Mid-eastern countries. Eastern Asia has a low prevalence of celiac disease due to both a lack of genetic predisposition and a low consumption of wheat. However, the potential for rising incidence of celiac disease has been described in Japan [1-3], because in the past decades the traditional rice-based diet has been replaced by a westernstyle diet, and now wheat consumption is as much as in India. The prevalence of HLA-DQ2 and DQ8, the two major haplotypes that play a major role in the development of celiac disease, have been reported to be as high as $30-40 \%$ in some Western countries. The prevalence of HLA-DQ2 and DQ8 in the general Japanese population is estimated to be around 10-20\%, substantially lower than in Western countries, but not absent. However, the precise prevalence of celiac disease in Japan remains unknown.

Diagnostic laboratory tests for celiac disease are not commonly used in Japan and there is a possibility of underdiagnosis or misdiagnosis as other inflammatory disorders of the gastrointestinal tract sharing similar clinical symptoms such as inflammatory bowel disease (IBD). 
Celiac disease, Crohn's disease, and ulcerative colitis are categorized as inflammatory disorders of the gastrointestinal tract of unknown etiology, although genetic, immunological and environmental factors are involved in their pathogenesis. Since the incidence of IBD has increased steadily in Japan, and as exposure to gluten containing food has become more common, it is possible that there is confusion in discriminating between celiac disease and IBD.

The most reliable serological marker of celiac disease, anti-tissue transglutaminase (tTG), appears to be seen in IBD patients as a result of immunological phenomena [46]. A wide range of anti-tTG concentrations has been demonstrated in IBD patients and their positive anti-tTG results are related to disease activity [4, 7]. However, a high rate of false positives has previously been reported, when guinea pig liver extracts were used as a source of tTG [8-10], and the more specific human recombinant tTG antigen is now widely used.

Histological evaluation followed by serology and small intestinal biopsy with villous atrophy is the gold standard for celiac disease diagnosis. However, villous atrophy and increased intraepithelial lymphocytosis has also been reported in Crohn's disease and other intestinal disorders [11], and IBD and celiac disease can superimpose each other. These serological and histological aspects make it difficult to evaluate the comorbidity of these two diseases.

The anti-endomysial antibodies (EMA) blood test is considered the most specific to celiac disease, but EMA lacks sensitivity especially in the early disease stage with mild villous atrophy $[12,13]$. More recent work has led to the development of serological tests that can identify antibody to deamidated gliadin peptides (DGP), the product of intestinal tTG action on dietary gluten peptide [14]. These peptides bind with high affinity to human leukocyte antigen (HLA) DQ2 or DQ8 on celiac patient antigenpresenting cells to potently stimulate the inflammatory $\mathrm{T}$ cell response [15]. This account for the antibody response for DGP is more highly specific for celiac disease than the historically used antibodies to native gluten (AGAs), so measurement of anti-DGP is reasonably specific [16], especially in children, in patients with early stage celiac disease and almost normal villous morphology [17], or to monitor diet compliance [18]. However, no study has evaluated this new food-related antibody in the diagnosis of celiac disease in IBD patients.

The condition with positive antibodies but without diagnostic villous atrophy is often considered false-positive, but there is evidence to suggest that such a finding is indicative of latent celiac disease [19], for which Furguson et al. introduced the term potential celiac disease [20]. Potential patients may develop a gluten-dependent enteropathy later. Such patients are increasing in number [21] and account for as many as $20 \%$ of patients with positive serology, yet there is no agreement on how to monitor their progress [22]. If the positivity for celiac-specific antibodies in IBD turns out to be false positive, another possibility to be evaluated is comorbidity of non-celiac gluten intolerance in IBD patients. However, there have been no previous reports about this aspect.

The aim of this study is therefore to examine the prevalence of celiac disease and celiac disease-specific antibodies in a Japanese population that is genetically less susceptible to celiac disease. Especially we focused on the prevalence of celiac disease-specific antibodies in IBD patients to elucidate possible complications. We used the autoantibody, tTG, and food-related antibody, DGP, in the first screening test and evaluated their occurrence in relation to clinical activities and other clinical characteristics of IBD patients. We further investigated participants with positive celiac disease-specific antibodies for genetic HLA testing and duodenal histological changes to confirm the diagnosis of celiac disease. Thereafter, to investigate the effect of gluten intake, we followed up some sero-positive IBD patients clinically, serologically and histologically with or without gluten containing diet prospectively.

\section{Materials and methods}

\section{Study population}

This cohort study was prospectively conducted in a single university institute between 2009 and 2012. All participants were Japanese and older than 16 years of age. The exclusion criteria were incomplete diagnosis of IBD, serious heart disease, liver cirrhosis, malignancies, and autoimmune disease such as type 1 diabetes mellitus (T1DM), rheumatoid arthritis, Sjogren's syndrome and autoimmune hepatitis (AIH). The study protocol was reviewed and approved by the institutional Review Board on April 16th, 2009. All patients provided written informed consent prior to study participation.

There were two study groups: an IBD group composed of 172 IBD patients, 62 with Crohn's disease [mean age: 38.5 (range 18-75), 42 male and 20 female] and 110 with ulcerative colitis [mean age: 47.7 (range 19-82), 60 male and 50 female]. The diagnosis of Crohn's disease and ulcerative colitis was confirmed by clinical, endoscopic, and histological findings according to standard diagnostic criteria. Disease activity was assessed according to the criteria of the Harvey-Bradshaw index (HBI) [23] and Mayo score [24]. The control group consisted of 190 asymptomatic patients [mean age: 64.6 (range 26-86), 115 male and 75 female] who were scheduled for surveillance colonoscopy either because of primary care referral or selfreferral. 
Study protocol

Each patient was screened for celiac disease-specific antibodies, tTG and DGP, and underwent other laboratory assessments, including IgA measurement. If patients showed positive for either antibody assay, they underwent an EMA assay, HLA testing and endoscopy with at least four duodenal biopsies to confirm the diagnosis of celiac disease. Patients with IBD also underwent HLA testing. To evaluate what the positivity of celiac disease-specific antibodies in IBD patients reflects, we also analyzed IBD-specific antibodies, anti-Saccharomyces cerevisiae antibody (ASCA) and perinuclear anti-neutrophil cytoplasmic antibody (p-ANCA), and to other food antigens. ASCA is known to be predominantly associated with Crohn's disease, and p-ANCA proposed as a marker for ulcerative colitis.

To evaluate the effect of gluten, we observed sero-positive patients with or without gluten restriction prospectively. Because there is no consensus regarding the follow-up of those sero-positive patients without diagnostic pathology, the choice either to continue with a normal gluten-containing diet (normal diet) or follow a gluten-restricted diet was offered. Fifteen of 25 patients positive for tTG agreed to participate in the follow-up trial. The gluten-restricted group was composed of six patients with IBD (four Crohn's disease, two ulcerative colitis) and two controls. The nonrestricted group was composed of seven patients with IBD (five Crohn's disease, two ulcerative colitis) and one control. Gluten-restricted diet was introduced by dietician, and food diaries were kept to ensure compliance. All participants were re-evaluated with respect to clinical symptoms, serum samples and duodenal biopsy at six months.

\section{Measurement of biomarkers}

Serum was analyzed for the following celiac disease-specific antibodies using a commercially available enzymelinked immunosorbent assay (ELISA): anti-human tTG immunoglobulin (Ig) A ELISA (Immuno Biological Laboratories Co., Ltd. Gunnma, Japan, Oregentec, Mainz, Germany), anti-DGP IgA ELISA (Oregentec Mainz, Germany) with reference range $<10 \mathrm{U} / \mathrm{ml}$, anti-gliadin IgG ELISA (Oregentec, Mainz, Germany) with reference range $<12 \mathrm{U} / \mathrm{ml}$, ASCA IgG/IgA ELISA (Oregentec, Mainz, Germany) with reference range $<10 \mathrm{U} / \mathrm{ml}$, and ANCA (Oregentec, Mainz, Germany) with reference range $<5 \mathrm{U} /$ $\mathrm{ml}$, and Food IgG ELISA (Biomerica, Inc. USA) with reference range $<50 \mathrm{U} / \mathrm{ml}$. Any celiac disease-specific antibody measurement over the manufacturer's reference range was considered to be positive.

Anti-endomysial IgA was examined by indirect immunofluorescence using monkey esophagus as the substrate (Mayo Clinic Laboratories, MN, USA). Celiac associated
HLA testing (HLA-DQ2 and HLA-DQ8) was performed using DR/DQ 2T Lotus SSP UniTray (Invitrogen, Life Technologies Japan, Ltd. Tokyo, Japan). For histological evaluation, at least four biopsy samples were obtained from the second and third portions of the duodenum using a forward viewing endoscope. All biopsy samples were placed in $10 \%$ formalin, embedded in paraffin wax cut on microtomes at $4 \mu \mathrm{m}$, stained with H\&E, and examined by a staff pathologist. The conclusion was confirmed by a second expert gastrointestinal pathologist. Histological features of celiac disease were in concordance with the modified Marsh criteria [25].

Statistical analysis

Quantitative data were expressed as medians and ranges or means and standard deviations. A 2-tailed Student $t$ test or Welch's $t$ test was used to compare laboratory values between groups, and a paired $t$ test or Wilcoxon signedrank test was used to compare changes within groups. The Mann-Whitney $U$ test was used to compare changes between groups in celiac-specific antibody values. The Chi square test in cross-tabulations was used to compare differences in clinical symptoms and disease localization and symptoms between groups. $P$ values $<0.05$ were considered statistically significant.

\section{Results}

Prevalence of celiac disease and disease-specific antibodies in Japanese IBD and control patients

As shown in Table 1, out of a total of 362 participants, 25 were tTG-positive, 24 were DGP-positive and 15 were positive for both. Of 172 IBD patients examined, 22 (12.8\%) had anti-tTG antibody levels above the cut-off value, while only three $(1.6 \%)$ out of 190 controls were positive. Similarly, $23(13.4 \%)$ of 172 had a positive DGP antibody test compared with only one $(0.5 \%)$ of 190 controls. Thus, the prevalence of celiac-specific antibodies was significantly higher in IBD patients than in controls $(p<0.01)$, and numerically higher in Crohn's disease compared with ulcerative colitis. The prevalence of tTG was 19.4 and $9.1 \%$ in Crohn's disease and ulcerative colitis, respectively $(p=0.053)$, and 19.4 and $10 \%$, respectively, for DGP $(p=0.083)$. About half of the patients positive for either tTG or DGP were positive for both antibodies.

A significant correlation was observed between TTG and DGP serum antibody concentrations $(r=0.517, p<0.05)$. As shown in Fig. 1, the concentration of each celiac disease-specific antibody ranged widely, but a marked increase in antibody concentrations was found in some IBD 
Table 1 Prevalence of celiac disease-specific antibodies in IBD and control

\begin{tabular}{|c|c|c|c|c|c|c|}
\hline \multirow[b]{2}{*}{ Number of patients } & \multicolumn{2}{|c|}{ Crohn's disease } & \multicolumn{2}{|c|}{ Ulcerative colitis } & \multirow{2}{*}{$\frac{\text { Control }}{(n=190)}$} & \multirow{2}{*}{$\frac{\text { Total }}{(n=362)}$} \\
\hline & $(n=62)$ & $p$ value* & $(n=110)$ & $p$ value $* *$ & & \\
\hline \multicolumn{7}{|l|}{ Elevated serum celiac disease-specific antibodies, $n(\%)$} \\
\hline tTG alone & $3(4.8)$ & $<0.001$ & $5(4.5)$ & $<0.001$ & $2(1.1)$ & 10 \\
\hline DGP alone & $3(4.8)$ & $<0.001$ & $6(4.5)$ & $<0.001$ & $0(0)$ & 9 \\
\hline Both tTG and DGP & $9(14.5)$ & $<0.001$ & $5(4.5)$ & $<0.001$ & $1(0.5)$ & 15 \\
\hline Negative for any serum celiac disease-specific antibodies, $n(\%)$ & $47(75.9)$ & $<0.001$ & $94(85.5)$ & $<0.001$ & $187(98.4)$ & 328 \\
\hline
\end{tabular}

$t T G$ serum tissue trans glutaminase $(\operatorname{Ig} \mathrm{A}), D G P$ serum deamidated gliadin peptide $(\operatorname{Ig} \mathrm{A})$

* Statistical comparisons between Crohn's disease and control

** Statistical comparisons between ulcerative colitis and control

Fig. 1 Serum concentration of celiac disease specific antibodies in IBD and control. Serum concentration of serum a tTG and $\mathbf{b}$ DGP in IBD and control. Dashed lines indicate the upper limit of normal level based on manufacturer's provided cut-off values. The $p$ values refer to the MannWhitney test calculated in IBD patients vs. controls $254 \times 190 \mathrm{~mm}(96 \times 96 \mathrm{DPI})$

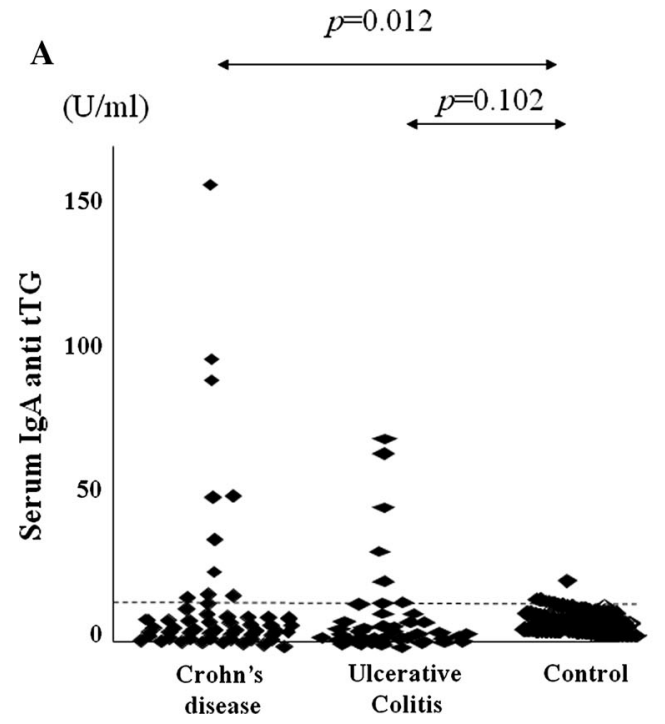

B

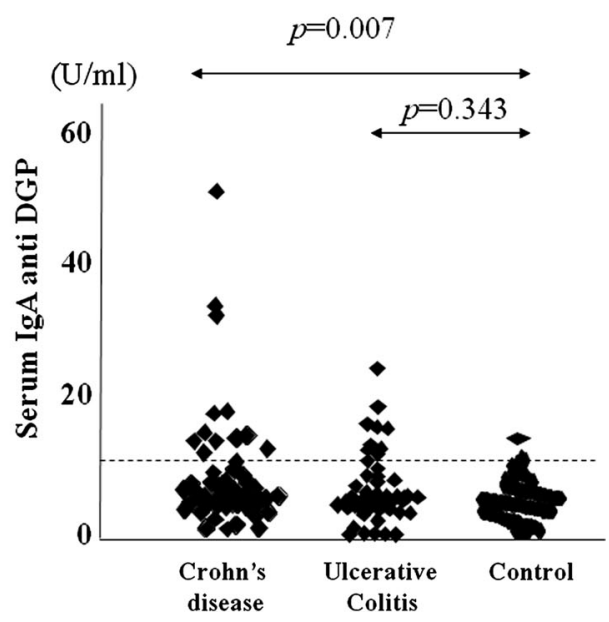

patients. By contrast, most results were close to the cut-off values in controls. Similar results were observed for DGP.

The relationship between the positivity of celiac diseasespecific antibodies and the clinical presentation of Crohn's disease and ulcerative colitis is shown in Tables 2 and 3. A highly significant correlation was found between the positivity of celiac-specific antibodies and disease activity in IBD patients, as determined by the HBI in Crohn's disease and Mayo score in ulcerative colitis. The antibody status was not affected by other factors such as duration of disease, extent or localization of disease, clinical types of disease, laboratory data including serum albumin, total cholesterol and hemoglobin, or medication.

As shown in Table 4, as previously reported ASCA was predominantly associated with Crohn's disease, and p-ANCA was exclusively associated with ulcerative colitis. However, in this study population, the positivity of p-ANCA and ASCA was not strongly correlated with the positivity of celiac disease-specific antibodies. On the other hand, the positive prevalence of $\operatorname{IgG}$ against wheat, egg, and milk was consistently greater in those IBD patients positive for celiac disease-specific antibodies than those who were sero-negative (both in the case of ulcerative colitis and Crohn's disease). Interestingly, the incidence of elevated food-related antibodies was relatively higher in Crohn's disease patients than that of ulcerative colitis.

Thirty-four patients positive for either antibody underwent EMA assay and HLA testing. EMA was undetectable in this population. As shown in Table 5, three IBD patients (two with Crohn's disease and one with ulcerative colitis) and one control carried HLA-DQ8, whereas no patients carried HLA-DQ2. The four celiac-specific antibody-positive patients carrying HLA-DQ8 nevertheless showed normal villous morphology in the duodenal mucosa, although one ulcerative colitis patient showed a slight increase in intraepithelial lymphocytes (IELs) (21 IELs/ 100 enterocytes).

Thirty of the 34 patients positive for celiac-specific antibodies underwent esophagogastroduodenoscopy with duodenal biopsy. None showed an endoscopic appearance suggestive of celiac disease (such as scalloped mucosal folds, or a decrease in the number or height of duodenal 
Table 2 Relation between the positivity of celiac disease specific antibodies and clinical presentation of Crohn's disease

\begin{tabular}{|c|c|c|c|c|c|c|}
\hline \multirow[b]{2}{*}{ Number of patients } & \multicolumn{3}{|l|}{$\mathrm{tTG}$} & \multicolumn{3}{|l|}{ DGP } \\
\hline & $\begin{array}{l}\text { Positive } \\
(n=12)\end{array}$ & $\begin{array}{l}\text { Negative } \\
(n=50)\end{array}$ & $p$-value* & $\begin{array}{l}\text { Positive } \\
(n=12)\end{array}$ & $\begin{array}{l}\text { Negative } \\
(n=50)\end{array}$ & $p$-value* \\
\hline Median age, year (range) & $37.5(23-52)$ & $38.8(18-75)$ & 0.691 & $38.2(24-64)$ & $38.6(18-75)$ & 0.940 \\
\hline Mean disease duration (year) & 9.5 & 10.1 & 0.374 & 10.2 & 9.6 & 0.813 \\
\hline Localization of the disease $(n)$ & & & 0.144 & & & 0.633 \\
\hline UGI & 2 & 4 & 0.312 & 3 & 3 & 0.074 \\
\hline Jejunum/ileum & 11 & 37 & 0.131 & 10 & 38 & 0.370 \\
\hline Colon & 10 & 37 & 0.320 & 8 & 34 & 0.608 \\
\hline Clinical type of disease $(n)$ & & & 0.467 & & & 0.482 \\
\hline Penetrating & 5 & 10 & 0.202 & 5 & 10 & 0.202 \\
\hline Structuring & 5 & 22 & 0.615 & 4 & 23 & 0.362 \\
\hline Inflammatory & 5 & 23 & 0.872 & 4 & 24 & 0.872 \\
\hline Stoma $(n)$ & 4 & 8 & 0.178 & 4 & 9 & 0.248 \\
\hline Medication $(n)$ & & & 0.482 & & & 0.979 \\
\hline Immunomodulators $^{* *}$ & 7 & 24 & 0.329 & 7 & 24 & 0.329 \\
\hline Corticosteroid & 1 & 8 & 0.461 & 2 & 9 & 0.663 \\
\hline Elemental diet & 9 & 32 & 0.299 & 7 & 36 & 0.856 \\
\hline Harvey-Bradshaw index (HBI) & $5.61 \pm 2.69$ & $1.31 \pm 0.80$ & $<0.01$ & $5.18 \pm 2.76$ & $1.25 \pm 0.20$ & $<0.01$ \\
\hline \multicolumn{7}{|l|}{ Laboratory values } \\
\hline Albumin $(\mathrm{g} / \mathrm{dl})$ & $3.83 \pm 0.84$ & $4.25 \pm 0.36$ & 0.312 & $4.10 \pm 0.65$ & $4.03 \pm 0.52$ & 0.695 \\
\hline Total cholesterol (mg/dl) & $138.7 \pm 43.0$ & $152.7 \pm 45.0$ & 0.397 & $143.2 \pm 43.7$ & $151.2 \pm 45.1$ & 0.651 \\
\hline Hemoglobin (g/dl) & $12.9 \pm 2.09$ & $12.7 \pm 2.04$ & 0.849 & $12.7 \pm 2.55$ & $12.9 \pm 1.94$ & 0.937 \\
\hline CRP (mg/dl) & $0.83 \pm 1.69$ & $0.86 \pm 2.38$ & 0.829 & $0.78 \pm 1.65$ & $0.54 \pm 0.57$ & 0.617 \\
\hline
\end{tabular}

$t T G$ serum tissue trans glutaminase (IgA), DGP serum deamidated gliadin peptide (IgA), UGI upper gastrointestinal tract, proximal to the jejunum, $C R P$ C-reactive protein. The data are presented as the mean values with standard deviations

* Statistical comparison between sero-positive and sero-negative

** Azathioprine, 6-mercaptopurine, and anti-TNF agents

folds). Only one patient with Crohn's disease had borderline histological features of celiac disease, with 28 IELs per 100 enterocytes, crypt hyperplasia, and mild villous atrophy. This patient also had non-caseous granuloma in the resected specimen of the affected colon, suggesting the possible co-morbidity of Crohn's disease and celiac disease. However, the patient carried HLA-DQ4 and DQ7 without HLA-DQ2/DQ-8, suggesting false-positive for celiac disease. Besides this case, an increased number of IELs was seen in the duodenal mucosa of four other celiacspecific antibody-positive IBD patients (one Crohn's disease and three ulcerative colitis) without evidence of villous atrophy. Among those IBD patients with an increased number of IELs, only one carried DQ8-DR4 (mentioned above); other IBD patients did not carry DQ2/DQ8.

The effect of gluten restriction on sero-positive patients

Of the 25 patients positive for tTG antibody, eight started a gluten-restricted diet, and eight continued a normal diet (unrestricted group). At the beginning of the study, all participants in both groups showed positive for anti-gliadin $\mathrm{IgG}$ antibody, and evinced abdominal symptoms. As shown in Fig. 2, after six months the anti-tTG concentrations were significantly decreased in the gluten-restricted group, whereas the unrestricted group showed persistently elevated anti-tTG levels. Similarly, serum concentrations of DGP were significantly decreased in the gluten-restricted group, while no interval change was observed in the unrestricted group. After 6 months on a gluten-restricted diet, the symptoms, especially the number of liquid stools per day, were alleviated in participants [number of liquid stool: from $6.2 \pm 3.9$ to $1.5 \pm 0.7(p=0.01)$ ], while no such change in the gluten-unrestricted group (from $4.0 \pm 1.9$ to $4.7 \pm 2.1$ ). When clinical response of IBD was defined as a reduction of 3 or more points in the score on the HBI or Mayo score at the evaluation, all IBD patients on gluten-restricted diet had good clinical response. On gluten-restricted diet, mean HBI improved from $7.5 \pm 2.12$ to $3 \pm 1.4$, and Mayo score improved 
Table 3 Relation between the positivity of celiac disease specific antibodies and clinical presentation of ulcerative colitis

\begin{tabular}{|c|c|c|c|c|c|c|}
\hline \multirow[b]{2}{*}{ Number of patients } & \multicolumn{3}{|l|}{ tTG } & \multicolumn{3}{|l|}{ DGP } \\
\hline & $\begin{array}{l}\text { Positive } \\
(n=10)\end{array}$ & $\begin{array}{l}\text { Negative } \\
(n=100)\end{array}$ & $p$ value* & $\begin{array}{l}\text { Positive } \\
(n=11)\end{array}$ & $\begin{array}{l}\text { Negative } \\
(n=99)\end{array}$ & $p$ value* \\
\hline Median age, year (range) & $47.5(19-82)$ & $47.8(25-68)$ & 0.958 & $42.0(19-82)$ & $48.1(24-68)$ & 0.950 \\
\hline Mean disease duration (year) & 12.8 & 9.3 & 0.462 & 11.0 & 9.6 & 0.586 \\
\hline Localization of the disease $(n)$ & & & 0.798 & & & 0.887 \\
\hline Pancolitis & 5 & 50 & 0.533 & 6 & 50 & 0.526 \\
\hline Left-sided colitis & 3 & 37 & 0.420 & 3 & 34 & 0.458 \\
\hline Proctitis & 2 & 13 & 0.408 & 2 & 15 & 0.534 \\
\hline Medication $(n)$ & & & 0.084 & & & 0.279 \\
\hline Immunomodulators $^{* *}$ & 5 & 27 & 0.089 & 5 & 29 & 0.221 \\
\hline Corticosteroid & 5 & 35 & 0.271 & 5 & 38 & 0.441 \\
\hline Mayo score & $6.40 \pm 1.80$ & $2.60 \pm 1.70$ & $<0.01$ & $6.10 \pm 1.9$ & $2.58 \pm 1.94$ & $<0.01$ \\
\hline \multicolumn{7}{|l|}{ Laboratory values } \\
\hline Albumin $(\mathrm{g} / \mathrm{dl})$ & $4.15 \pm 0.36$ & $4.21 \pm 0.48$ & 0.987 & $4.15 \pm 0.08$ & $4.14 \pm 0.60$ & 0.950 \\
\hline Total cholesterol (mg/dl) & $173.1 \pm 24.5$ & $180.0 \pm 30.7$ & 0.358 & $163.4 \pm 20.3$ & $179.7 \pm 31.1$ & 0.03 \\
\hline Hemoglobin (g/dl) & $12.6 \pm 1.52$ & $13.8 \pm 2.30$ & 0.107 & $13.1 \pm 1.63$ & $13.5 \pm 1.75$ & 0.953 \\
\hline CRP (mg/dl) & $0.30 \pm 0.31$ & $0.19 \pm 1.49$ & 0.131 & $0.27 \pm 0.25$ & $0.20 \pm 1.51$ & 0.145 \\
\hline
\end{tabular}

$t T G$ serum tissue trans glutaminase (IgA), DGP serum deamidated gliadin peptide (IgA), CRP C-reactive protein

* Statistical comparison between sero-positive and sero-negative

** Azathioprine, 6-mercaptopurine, calcineurin inhibitor (tacrolimus) and anti-TNF agents

Table 4 Relation between the positivity of celiac disease-specific antibodies, IBD-specific antibodies, and food-related antibodies

\begin{tabular}{|c|c|c|c|c|c|c|}
\hline \multirow[b]{2}{*}{$\begin{array}{l}\text { Celiac serology } \\
\text { Number of patients }\end{array}$} & \multicolumn{3}{|c|}{ Crohn's disease } & \multicolumn{3}{|c|}{ Ulcerative colitis } \\
\hline & $\begin{array}{l}\text { Positive* } \\
(n=15)\end{array}$ & $\begin{array}{l}\text { Negative** } \\
(n=47)\end{array}$ & $p$ value $* * *$ & $\begin{array}{l}\text { Positive* } \\
(n=16)\end{array}$ & $\begin{array}{l}\text { Negative** } \\
(n=94)\end{array}$ & $p$ value $* * *$ \\
\hline \multicolumn{7}{|c|}{ Positive IBD-specific antibodies, $n(\%)$} \\
\hline ASCA IgA/IgG & $8(53.5)$ & $29(61.7)$ & 0.57 & $2(12.5)$ & $17(18.1)$ & 0.59 \\
\hline p-ANCA & 0 & 0 & & $1(6.25)$ & $5(5.3)$ & 0.57 \\
\hline \multicolumn{7}{|c|}{ Positive food-related antibodies, $n(\%)$} \\
\hline Wheat IgE & $2(13.3)$ & $0(0)$ & 0.01 & $1(6.25)$ & $0(0)$ & 0.08 \\
\hline Milk IgG & $13(86.6)$ & $30(63.8)$ & 0.09 & $12(75)$ & $62(65.9)$ & 0.57 \\
\hline Egg IgG & $15(100)$ & $30(63.8)$ & 0.10 & $8(50.0)$ & $40(41.7)$ & 0.43 \\
\hline Wheat IgG & $9(60)$ & $19(40.4)$ & 0.189 & $1(6.3)$ & $4(4.3)$ & 0.67 \\
\hline Pork IgG & $0(0)$ & $0(0)$ & & $0(0)$ & $0(0)$ & \\
\hline
\end{tabular}

ASCA anti-Saccharomyces cervisiae antibody, $p$-ANCA perinuclear anti-neutrophil cytoplasmic antibody

* Positive for either tTG or DGP

** Negative for both tTG and DGP

*** Statistical comparison between sero-positive and sero-negative

from $8 \pm 0.5$ to $2.5 \pm 0.5$, mainly due to the decrease of bloody stool frequency, although colonoscopic activity of IBD was almost unchanged between the evaluations. On gluten-containing diet, in contrast, Mayo score and HBI did not change during the observation period, from $6 \pm 0$ to $6.5 \pm 0.7, \quad 3.6 \pm 0.9$ to $4.2 \pm 1.1$, respectively. An improvement of laboratory values [CRP from $0.97 \pm 1.3$ $(\mathrm{mg} / \mathrm{dl}) \quad$ to $0.60 \pm 0.58 \quad(p=0.16), \quad$ albumin from $4.0 \pm 0.37(\mathrm{~g} / \mathrm{dl})$ to $4.3 \pm 0.27(p=0.94)$, and hemoglobin from $12.1 \pm 2.4(\mathrm{~g} / \mathrm{dl})$ to $13.8 \pm 1.6(p=0.89)]$ was also observed in the gluten-restricted group, but not in the gluten-unrestricted group. Although, the overall change in laboratory values was not statistically significant between the gluten-restricted and unrestricted groups. During the six 
Table 5 HLA testing and duodenal biopsy findings in sero-positive IBD and control

\begin{tabular}{|c|c|c|c|c|c|}
\hline \multicolumn{2}{|c|}{ Number of patients with positive for tTG or DGP $(n)$} & \multirow{2}{*}{$\begin{array}{l}\text { Crohn's disease } \\
(n=15)\end{array}$} & \multirow{2}{*}{$\begin{array}{l}\text { Ulcerative colitis } \\
(n=16)\end{array}$} & \multirow{2}{*}{$\begin{array}{l}\text { Control } \\
(n=3)\end{array}$} & \multirow{2}{*}{$\frac{\begin{array}{l}\text { Total } \\
(n=34)\end{array}}{4}$} \\
\hline HLA type $(n)$ & DQ8 & & & & \\
\hline & DQ2 & 0 & 0 & 0 & 0 \\
\hline \multicolumn{2}{|c|}{ Number of sero-positive patients with duodenal biopsy $(n)$} & $\begin{array}{l}\text { Crohn's disease } \\
(n=13)\end{array}$ & $\begin{array}{l}\text { Ulcerative colitis } \\
(n=14)\end{array}$ & $\begin{array}{l}\text { Control } \\
(n=3)\end{array}$ & $\begin{array}{l}\text { Total } \\
(n=30)\end{array}$ \\
\hline \multicolumn{2}{|c|}{ Mild villous atrophy and increased IELs $(n)$} & 1 & 0 & 0 & 1 \\
\hline \multicolumn{2}{|c|}{ Increased IELs only $(n)$} & 1 & 3 & 0 & 4 \\
\hline
\end{tabular}

$t T G$ serum tissue trans glutaminase (IgA), DGP serum deamidated gliadin peptide (IgA), EMA serum anti-endomysial antibody, HLA human leukocyte antigen, IEL intraepithelial lymphocyte
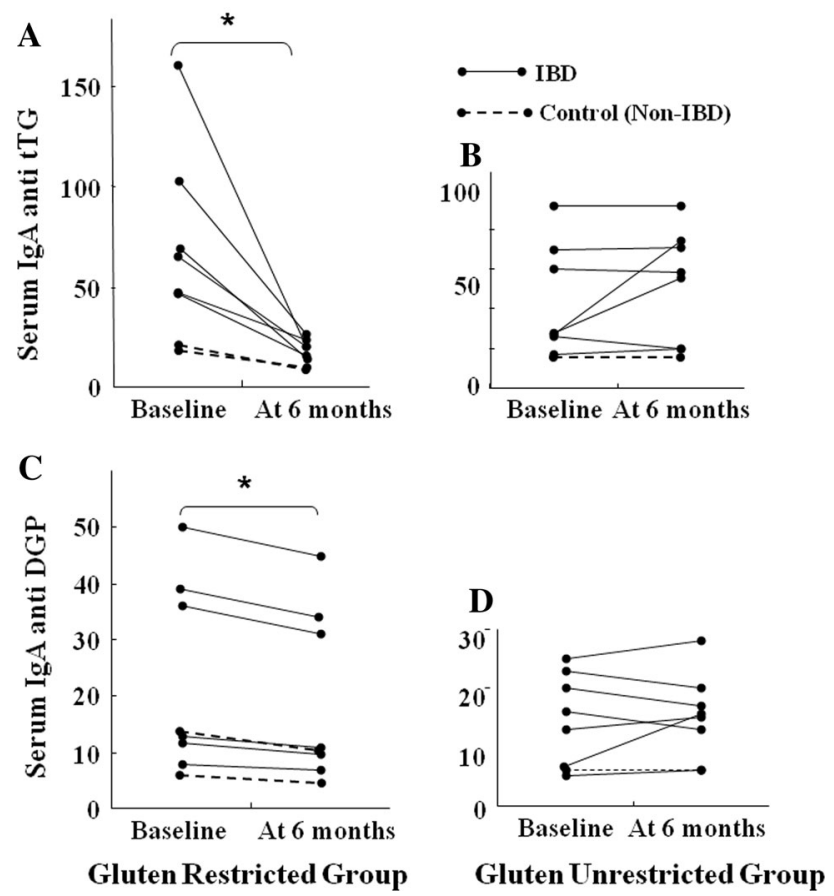

Fig. 2 Effect of gluten restriction on sero-positive patients. Effect of gluten restriction on sero-positive patients. Serum a tTG and c DGP of the participants before and after 6 month with gluten restricted diet. Serum $\mathbf{b}$ tTG and $\mathbf{d}$ DGP of the participants with before and after 6 month with gluten unrestricted diet. Asterisk change within the group significant compared with baseline; $p<0.01190 \times 254 \mathrm{~mm}$ $(96 \times 96 \mathrm{DPI})$

months follow-up period, none of the participants showed histologic change characteristic of celiac disease by duodenal biopsy on a gluten-containing diet.

\section{Discussion}

This is the first report regarding the prevalence of celiac disease according to both serology and biopsy in Japanese population. Out of 470 participants, biopsy-defined celiac disease could not be confirmed in any. While some suspected cases of celiac disease have been reported in Japan in the past, these lack confirmation with a new sensitive serological recombinant human tTG assay or duodenal pathology [1-3]. As for serological examination, the world wide overall the positivity of tTG $\operatorname{IgA}$ is $0.3-3.2 \%$ [26-28]. In this study, the positivity of the tTG $\operatorname{IgA}$ in the control group was $1.6 \%$. On the other hand, the positivity is reported higher in IBD patients [29-31]. According to the recent studies, using a human recombinant tTG, the prevalence of tTG in Crohn's disease and ulcerative colitis is $0-27.2 \%[29,30]$ and $1-12 \%[29,31]$, respectively. In this study, the prevalence of tTG was 19.4 and $9.1 \%$ in Crohn's disease and ulcerative colitis, respectively. These data suggest that the prevalence of tTG in Japanese patients may not be significantly different from that in other populations. However, in contrast to the aforementioned study, there was no definite cases of celiac disease in this study. It has been suggested that celiac disease is rare in Japan due to genetic factors; therefore, a larger-scale cohort study in Japan is required in future.

Celiac disease is difficult to diagnose particularly in a patient already suffering from IBD as the two conditions have many symptoms in common. Even the most characteristic findings of celiac disease, scalloped duodenal mucosal folds or villous atrophy, can be seen in patients with Crohn's disease [32-34], and increased intraepithelial lymphocytosis (Marsh Type 1-2) is a non-specific finding of Crohn's disease [33, 34]. HLA testing in combination with other serological tests can often help to exclude celiac disease; however, multicenter trials have shown that $0.5 \%$ of patients with celiac disease are both HLA-DQ2- and HLA-DQ8- negative [35].

The present study is the largest study on the prevalence of celiac-specific antibodies in IBD patients and controls in a population lacking a genetic disposition. We used both tTG and DGP as the initial screening test, because food related antibody, DGP, shows higher sensitivity in very early stage celiac patients $[17,36]$ and has been suggested to be less frequently elevated in autoimmune diseases; 
some studies described a moderate tTG increase in organspecific autoimmune disease and IBD [5]. The observed higher prevalence of both celiac-specific antibodies in IBD patients was not surprising. The prevalence of tTG in other organ-specific autoimmune diseases, T1DM and $\mathrm{AIH}$, was $1 / 32$ and $1 / 38$, respectively, which is lower than the positive rate in IBD patients (22/172). These results suggest that other factors may affect the aberrant immunological characteristics in the gastrointestinal tract, such as food intolerance.

It has been reported that tTG is over-expressed in apoptotic tissue and its expression is related to the inflamed intestinal mucosa of IBD patients [37]. A previous study reported an increase in tTG antibodies that was correlated with disease activity [4]. Our tTG data support this view, and observed similar findings with DGP. In the case of ulcerative colitis, a humoral-type immunological response with increased synthesis of antibodies is known to play a predominant role. In this study, the high prevalence and weak positive for celiac disease-specific antibodies perhaps reflects dysregulation of the immune system in ulcerative colitis together with accidental cross-reactivity with environmental antigens, such as gliadin. On the other hand, the high prevalence of celiac-specific antibodies in Crohn's disease with higher titers possibly reflects the intestinal mucosal barrier defects, since the positive prevalence of IgG against milk, wheat and egg was greater than in ulcerative colitis, and in those positive rather than sero-negative for celiac disease-specific antibodies, although the difference was not statistically significant. The mucosal barrier defects, such as increased intestinal tight junction permeability [3840], may lead to increase antigen presentation and therefore generate auto-antibodies and food-related antibodies. This could reasonably perpetuate or exacerbate mucosal inflammation in Crohn's disease. It is conceivable that it induces a high celiac antibody titer even in Japanese who are genetically not predisposed to celiac disease. Another non-DQ2restricted mechanism is that gluten itself can induce injury and change in epithelial cells. That is gliadin increases epithelial permeability, alters protein expression of tight junction components and induces apoptosis. It can also inhibit RNA and DNA synthesis [41-43].

Indeed, we found that celiac-specific antibody-positive patients with IBD showed anti-gliadin IgG positive, which imply underlying gluten sensitivity in IBD. IBD patients have often reported dietary intolerance affecting their symptomatology [44]. This study was the first to describe an actual decrease of celiac specific antibodies in IBD patients with gluten-restricted diet together with clinical improvement. There have been no reports about comorbidity of non-celiac gluten sensitivity in IBD patients. However the current study is not designed to directly address the issue of gluten sensitivity in IBD patients.
The possible interpretation of the positivity of celiacspecific antibodies in Japanese IBD patients is mainly a false-positive one (i.e. without genetic gluten intolerance), but there remains a small possibility of true-positive (i.e. genetic gluten intolerance) with potential celiac disease. It has been reported that approximately $33 \%$ of patients with potential celiac disease were reported to develop villous atrophy during a three-year observation period [45]. In the current study, we prospectively observed sero-positive patients with or without gluten restriction for three years. However, to date, no biopsy-proven celiac disease patient has been found. After six months, anti-tTG titers decreased significantly in the gluten-restricted group. Interestingly, the dietary exclusion of wheat improved GI symptoms and serology in sero-positive IBD patients. It is possible that the exposure to dietary antigens, including gluten, is increased during active disease in IBD patients, although the prevalence of gluten sensitivity in patients with IBD and its impact on the clinical status of disease should be further investigated. In addition, the regular quantitative monitoring of $\mathrm{tTG}$ and DGP titers during patient management remains controversial and warrants further study.

The incidence of IBD has dramatically increased in the past 30 years in Japan, likely due to the introduction of Western life style and diet. The pathogenesis of IBD has been proposed to be a combination of genetic, immunologic and environmental factors. The prevalence of NOD2 mutations was rare in Eastern Asian countries, but still the incidence of IBD has seen an increase [46]. Our study suggests that this is unlikely the case in celiac disease, where the genetic component is much stronger compared to IBD. The incidence of celiac disease in the Middle-eastern and in some Asian countries such as India has been increasing [47], but this appears to be due to the high prevalence of HLA-DQ2/DQ8 as compared to the Japanese population.

There are several limitations to our study. It is possible that we underestimated the true prevalence of biopsy-proven celiac disease in IBD patients. Patchy histologic abnormality is reported in celiac disease and it is conceivable that sampling errors may have occurred. However, serial examinations on those on non-restricted diet still did not reveal any cases of celiac disease. We note that no accurate information regarding diet was collected prior to study initiation, thus some patients may unconsciously have avoided food containing gluten prior to testing. Finally, we could not include every positive patient with celiac-specific antibodies to evaluate the response to a gluten-restricted diet, although, none of them went on to develop diagnostic villous atrophy of celiac disease during the follow-up period.

In conclusion, we have shown while a certain proportion of IBD patients with GI symptoms were positive for celiac 
specific antibodies in a genetically un-predisposed population, there were no cases confirmed as celiac disease. Contrary to IBD, whose incidence has continued to rise, celiac disease appears to remain rare in Japan. Further investigation is needed to elucidate the etiologic mechanism of positive celiac specific antibodies and the clinical significance of a response to a gluten-restricted diet in IBD patients.

Acknowledgments This study was supported in part by Health and Labour Sciences Research Grants for research on intractable diseases from Ministry of Health, Labour and Welfare of Japan, Grants-in-Aid for Scientific Research from the Japanese Ministry of Education, Culture, Sports, Science and Technology and by grants from the National Defense Medical College.

Conflict of interest All authors declare that they have no conflict of interest.

\section{References}

1. Freeman HJ. Biopsy-defined adult celiac disease in AsianCanadians. Can J Gastroenterol. 2003;17:433-6.

2. Makishima H, Komiyama Y, Asano N, Momose K, Nakamura S, Ishida F. Peripheral T-cell lymphoma following diffuse large B-cell lymphoma associated with celiac disease. Intern Med. 2008;47:295-8.

3. Shaoul R, Marcon MA, Okada Y, Cutz E, Forstner G. Gastric metaplasia: a frequently overlooked feature of duodenal biopsy specimens in untreated celiac disease. J Pediatr Gastroenterol Nutr. 2000;30:397-403.

4. Di Tola M, Sabbatella L, Anania MC, Viscido A, Caprilli R, Pica R, et al. Anti-tissue transglutaminase antibodies in inflammatory bowel disease: new evidence. Clin Chem Lab Med. 2004;42:1092-7.

5. Bizzaro N, Villalta D, Tonutti E, Doria A, Tampoia M, Bassetti $\mathrm{D}$, et al. IgA and IgG tissue transglutaminase antibody prevalence and clinical significance in connective tissue diseases, inflammatory bowel disease, and primary biliary cirrhosis. Dig Dis Sci. 2003;48:2360-5.

6. Sblattero D, Berti I, Trevisiol C, Marzari R, Tommasini A, Bradbury A, et al. Human recombinant tissue transglutaminase ELISA: an innovative diagnostic assay for celiac disease. Am J Gastroenterol. 2000;95:1253-7.

7. D'Argenio G, Biancone L, Cosenza V, Della Valle N, D'Armiento FP, Boirivant M, et al. Transglutaminases in Crohn's disease. Gut. 1995;37:690-5.

8. Carroccio A, Giannitrapani L, Soresi M, Not T, Iacono G, Di Rosa C, et al. Guinea pig transglutaminase immunolinked assay does not predict coeliac disease in patients with chronic liver disease. Gut. 2001;49:506-11.

9. Clemente MG, Frau F, Musu MP, De Virgilis S. Antibodies to tissue transglutaminase outside celiac disease. Ital J Gastroenterol Hepatol. 1999;6:546.

10. Leon F, Camarero C, R-Pena R, Eiras P, Sanchez L, Baragaño M, et al. Anti-transglutaminase IgA ELISA: clinical potential and drawbacks in celiac disease diagnosis. Scand J Gastroenterol. 2001;36:849-53.

11. Schuffler MD, Chaffee RG. Small intestinal biopsy in a patient with Crohn's disease of the duodenum. The spectrum of abnormal findings in the absence of granulomas. Gastroenterology. 1979;76:1009-14.
12. Rostami K, Kerckhaert J, Tiemessen R. Sensitivity of antiendomysium and antigliadin antibodies in untreated celiac disease: disappointing in clinical practice. Am J Gastroenterol. 1999; 94:888-94.

13. Abrams JA, Diamond B, Rotterdam H, Green PH. Seronegative celiac disease: increased prevalence with lesser degrees of villous atrophy. Dig Dis Sci. 2004;49:546-50.

14. Schwertz E, Kahlenberg F, Sack U, Richter T, Stern M, Conrad $\mathrm{K}$, et al. Serologic assay based on gliadin-related nonapeptides as a highly sensitive and specific diagnostic aid in celiac disease. Clin Chem. 2004;50:2370-5.

15. Schuppan D, Junker Y, Barisani D. Celiac disease: from pathogenesis to novel therapies. Gastroenterology. 2009;137:1912-33.

16. Husby S, Koletzko S, Korponay-Szabó IR, Mearin ML, Phillips A, Shamir R, et al. European society for pediatric gastroenterology, hepatology, and nutrition guidelines for the diagnosis of coeliac disease. J Pediatr Gastroenterol Nutr. 2012;54:136-60.

17. Kurppa K, Lindfors K, Collin P, Saavalainen P, Partanen J, Haimila $\mathrm{K}$, et al. Antibodies against deamidated gliadin peptides in early-stage celiac disease. J Clin Gastroenterol. 2011;45: $673-8$.

18. Monzani A, Rapa A, Fonio P, Tognato E, Panigati L, Oderda G. Use of deamidated gliadin peptide antibodies to monitor diet compliance in childhood celiac disease. J Pediatr Gastroenterol Nutr. 2011;53:55-60.

19. Mäki M, Holm K, Lipsanen V, Hällström O, Viander M, Collin P, et al. Serological markers and HLA genes among healthy firstdegree relatives of patients with coeliac disease. Lancet. 1991;338:1350-3.

20. Ferguson A, Arranz E, O’Mahony S. Clinical and pathological spectrum of coeliac disease-active, silent, latent, potential. Gut. 1993;34:150-1.

21. Paparo F, Petrone E, Tosco A, Maglio M, Borrelli M, Salvati VM, et al. Clinical, HLA, and small bowel immunohistochemical features of children with positive serum antiendomysium antibodies and architecturally normal small intestinal mucosa. Am J Gastroenterol. 2005;100:2294-8.

22. Troncone R, Jabri B. Coeliac disease and gluten sensitivity. J Intern Med. 2011;269:582-90.

23. Harvey RF, Bradshaw JM. A simple index of Crohn's-disease activity. Lancet. 1980;1:514.

24. Schroeder KW, Tremaine WJ, Ilstrup DM. Coated oral 5-aminosalicylic acid therapy for mildly to moderately active ulcerative colitis. A randomized study. N Engl J Med. 1987;317: 1625-9.

25. Marsh MN. Grains of truth: evolutionary changes in small intestinal mucosa in response to environmental antigen challenge. Gut. 1990;31:111-4.

26. van der Windt DA, Jellema P, Mulder CJ, Kneepkens CM, van der Horst HE. Diagnostic testing for celiac disease among patients with abdominal symptoms: a systematic review. JAMA. 2010;303:1738-46.

27. Mustalahti K, Catassi C, Reunanen A, Fabiani E, Heier M, McMillan S, et al. The prevalence of celiac disease in Europe: results of a centralized, international mass screening project. Ann Med. 2010;42:587-95.

28. Barada K, Bitar A, Mokadem MA, Hashash JG, Green P. Celiac disease in Middle Eastern and North African countries: a new burden? World J Gastroenterol. 2010;16:1449-57.

29. Bizzaro N, Villalta D, Tonutti E, Doria A, Tampoia M, Bassetti $\mathrm{D}$, et al. IgA and IgG tissue transglutaminase antibody prevalence and clinical significance in connective tissue diseases, inflammatory bowel disease, and primary biliary cirrhosis. Dig Dis Sci. 2003;48:2360-5.

30. Ribeiro-Cabral VL, da-Silva-Patrício FR, Ambrogini-Junior O, Jankiel-Miszputen S. Anti-tissue transglutaminase antibodies 
(IgA and $\mathrm{IgG}$ ) in both Crohn's disease and autoimmune diabetes. Rev Esp Enferm Dig. 2011;103:453-7.

31. Tavakkoli H, Haghdani S, Adilipour H, Daghaghzadeh H, Minakari M, Adibi P, et al. Serologic celiac disease in patients with inflammatory bowel disease. J Res Med Sci. 2012;17:154-8.

32. Ludvigsson JF, Brandt L, Montgomery SM, Granath F, Ekbom A. Validation study of villous atrophy and small intestinal inflammation in Swedish biopsy registers. BMC Gastroenterology. 2009;9:19.

33. Wright CL, Riddell RH. Histology of the stomach and duodenum in Crohn's disease. Am J Surg Pathol. 1998;22:383-90.

34. Yang A, Chen Y, Scherl E. Inflammatory bowel disease in patients with celiac disease. Inflamm Bowel Dis. 2005;11:528-32.

35. Karell K, Louka AS, Moodie SJ. HLA types in celiac disease patients not carrying the DQA1*05-DQB1*02 (DQ2) heterodimer: results from the European Genetics Cluster on Celiac Disease. Hum Immunol. 2003;64:469-77.

36. Liu E, Li M, Emery L, Taki I, Barriga K, Tiberti C, et al. Natural history of antibodies to deamidated gliadin peptides and transglutaminase in early childhood celiac disease. J Pediatr Gastroenterol Nutr. 2007;45:293-300.

37. Farrace MG, Picarelli A, Di Tola M, Sabbatella L, Marchione OP, Ippolito G, et al. Presence of anti- "tissue" transglutaminase antibodies in inflammatory intestinal diseases: an apoptosisassociated event? Cell Death Differ. 2001;8:767-70.

38. Söderholm JD, Olaison G, Peterson KH, Franzén LE, Lindmark $\mathrm{T}$, Wirén $\mathrm{M}$, et al. Augmented increase in tight junction permeability by luminal stimuli in the non-inflamed ileum of Crohn's disease. Gut. 2002;50:307-13.

39. Schmitz H, Barmeyer C, Fromm M, Runkel N, Foss HD, Bentzel $\mathrm{CJ}$, et al. Altered tight junction structure contributes to the impaired epithelial barrier function in ulcerative colitis. Gastroenterology. 1999;116:301-9.

40. Schürmann G, Brüwer M, Klotz A, Schmid KW, Senninger N, Zimmer KP. Transepithelial transport processes at the intestinal mucosa in inflammatory bowel disease. Int $\mathrm{J}$ Colorectal Dis. 1999; 14:41-6.

41. Sander GR, Cummins AG, Henshall T, Powell BC. Rapid disruption of intestinal barrier function by gliadin involves altered expression of apical junctional proteins. FEBBS Lett. 2005;579:4851-5.

42. Elli L, Dolfini E, Bardella MT. Gliadin cytotoxicity and in vitro cell cultures. Toxicol Lett. 2003;146:1-8.

43. Hadjivassiliou M, Williamson CA, Woodroofe N. The immunology of gluten sensitivity: beyond the gut. Trend Immunol. 2004;25:578-82.

44. Bentz S, Hausmann M, Piberger H, Kellermeier S, Paul S, Held $\mathrm{L}$, et al. Clinical relevance of $\mathrm{IgG}$ antibodies against food antigens in Crohn's disease: a double-blind cross-over diet intervention study. Digestion. 2010;81:252-64.

45. Tosco A, Salvati VM, Auricchio R, Maglio M, Borrelli M, Coruzzo A, et al. Natural history of potential celiac disease in children. Clin Gastroenterol Hepatol. 2011;9:320-5.

46. Inoue N, Tamura K, Kinouchi Y, Fukuda Y, Takahashi S, Ogura $\mathrm{Y}$, et al. Lack of common NOD2 variants in Japanese patients with Crohn's disease. Gastroenterology. 2002;123:86-91.

47. Makharia GK, Verma AK, Amarchand R, Bhatnagar S, Das P, Goswami A, et al. Prevalence of celiac disease in the northern part of India: a community based study. J Gastroenterol Hepatol. 2011;26:894-900. 